\section{My Dear Mother}

The worst influenza pandemic of the last century occurred in 1918. Called "the Spanish Flu," the illness caused at least 30000 (some estimate 50 000) deaths in Canada. The following are excerpts from unpublished letters written by Annie Laird, a young mother living on an isolated Prairie farm in Manitoba, to her mother, Mrs. R. Penman, in Victoria, BC. Communication was by mail and, in an emergency, such as death, by telegram. Doctors covered large geographic areas. They had to be located and fetched.

Sunday, Oct. I $3^{\text {th, }}$ I9I8

... Aunty Mary was sick and fainted, Inez and Grandma both had bad colds and coughs, the house was like a hospital. I suppose it's this new fashioned Grippe, Spanish Influenza.

Sunday, Nov. I7th, I9I8

... A traveler had come there asking to stay all night. ... He was too ill to go on, and he gave them the Influenza. ... Ernest had a letter from Wesley Robb of Tisdale, former Swan Lake butcher; he said Edna was home and they were all sick except her and Dan. Dan left Monday morning for Tisdale, 40 miles, to get the Dr., and got back late Tues., and Mary died sometime on Wed., Nov 6. The Dr. was sick too and unable to go. Dan got some medicine, but it was too late. Poor Mary, she would be buried in a strange land, and likely there would be no minister or funeral, everyone would be afraid to go, for it must be very virulent. They would not have good ventilation or much fresh air in their low shack. ... I have not heard $\infty$ of any more cases or deaths in this part, but it is getting worse in Winnipeg. ... Eva had got a telegram with just the four words "Your Mother is dead." ... Eva had no letter for two weeks, and none since the telegram, and she thinks they all must be sick. ...

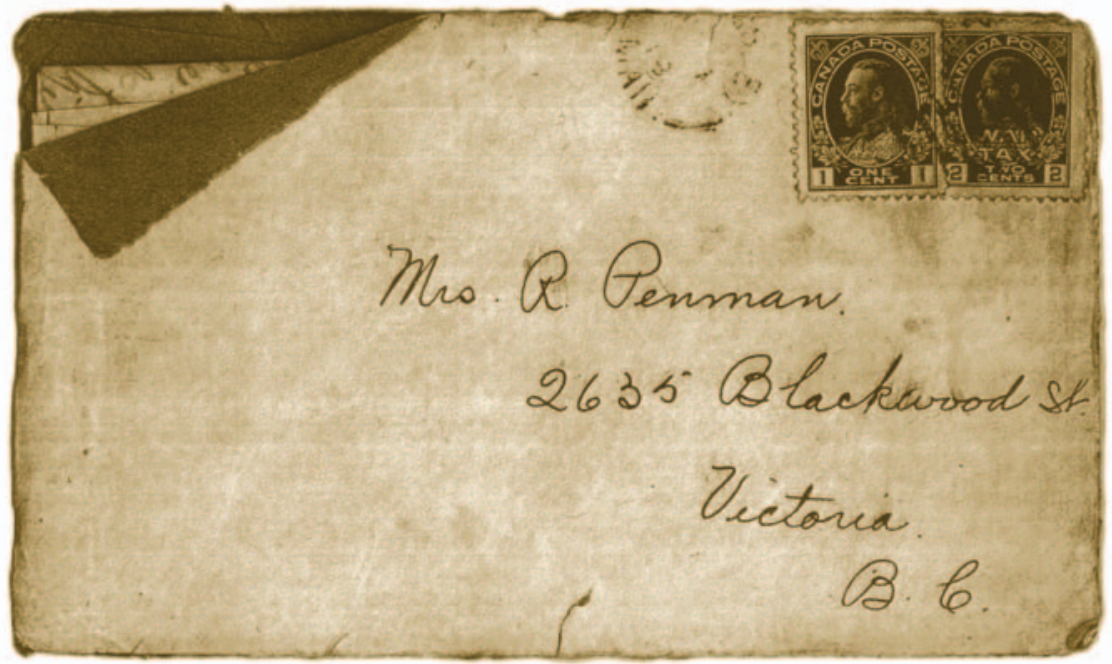

Sunday, Dec. I5th, I9I8

Hudson was buried last Sunday, and Jim McDonald on Monday, all the others are recovering. ... Will went up to the graveyard from Horn's. Mr. Lee conducted the service, there were very few there, not even the McD's themselves, they were all in bed. Jim felt pretty well, got up and washed himself, took cold, and pneumonia soon finished him. Whenever he died they put the body outside to freeze to keep down the infection. ... Maggie Deamal and her oldest girl aged II are dead with it, a younger girl dying, and two nurses who were taking care of them, both in bed. ... Shatford had been in La Riviere that morning and heard that there were I40 new cases in Winnipeg last Sunday and I4 deaths Mon. forenoon.

Sunday, Dec. 29th, I9I8

The Flu is still bad in La Riviere, and raging around St. Leon; there were three deaths there on Christmas Day. Dr. Rocan had 52 calls in one day. ... For five days and nights he got no sleep except what he snatched in the cutter. He had a driver and changed horse. His territory extended from Treherne to Kingsley and from Lourdes to Mariopolis.

Annie Laird and her family escaped the Spanish Flu, but the fear remained for several winters thereafter. The family does get "the Flu" in 1920. Although Annie is sure it is "no ordinary Grippe," the numbers of deaths are not those of 1918 , and most people, including Annie and her family, survive.

Sunday, Feb. I5th, I920

The whole house is reeking with carbolic, perhaps this letter will smell of it. Flu is around again, so we are keeping a tin of water and creosole on the stove as we did last winter. All the Hendersons and Shatfords were down with it last week ... I haven't heard how they are, for there has been another big blizzard and oh such drifts! ... the thermometer went down to 33 below.

Monday, March 8th, I920

It is my turn to write lying down, we've all had the Flu. ... Will was able to crawl around, heat lids for us and give us medicine, and he never had his clothes off night nor day since it is a hard deal for him and he is very tired. ... The neighbours have come and done the chores nights and mornings. ... Willie Henderson's second girl has it in both lungs and they have slight hope for her. ... Mrs. Chas Ridley died from it on Wednesday. Her mother came out and will likely take her children, a boy about 6 yrs and a baby almost 2.... It is an awful scourge, but not so dangerous as last year. 